\title{
Oestrus and gastric secretion in the dog
}

\author{
JOHN H. LANDOR ${ }^{1}$ AND ROBERT A. WILD \\ From the Department of Surgery, University of Missouri School of Medicine, Columbia, Missouri, USA
}

SUMMARY Marked decreases in 24-hour Heidenhain pouch secretion, lasting from nine to 18 days, were observed in five mongrel bitches during periods of naturally occurring oestrus. Neither oophorectomy nor control celiotomy caused significant change in Heidenhain pouch secretion in bitches who were not experiencing oestrus. The oral administration of diethyl stilboestrol, in doses ranging between $5 \mathrm{mg}$ and $70 \mathrm{mg}$ per day, had no clear-cut effect on Heidenhain pouch secretion.

Our interest in the possible effect of hormonal changes on gastric secretion in female dogs was aroused by a recent chance observation. While observing a group of dogs with Heidenhain pouches, preparatory to their being used in various experiments, we noted that the daily secretion of one of the bitches decreased quite precipitously after it had been at a stable plateau for several weeks. Investigation of possible causes for this hyposecretion revealed no obvious illness, no decrease in food intake, and no recent changes in the routine handling of the animal. Eventually, our technician noted that the animal was in heat and brought this fact to our attention. Since it seemed possible that this condition might be responsible for the noted change in secretion, we determined to watch carefully for signs of oestrus in other bitches with gastric pouches in the future. In addition, as a preliminary inquiry into mechanisms which might be causally related to the influence of oestrus on gastric secretion, we examined the effect of certain changes in the hormonal milieu on the secretion of gastric juice in dogs.

\section{Method}

Mongrel dogs, weighing between $13.8 \mathrm{~kg}$ and $18.7 \mathrm{~kg}$, were used throughout. The animals were maintained on a standard kennel ration and were allowed to eat during a one-hour period each morning. The amount of food consumed was recorded daily and the animals were weighed at weekly intervals. Gastric juice from the Heidenhain pouches was collected in rubber balloons attached to the cannulae in the pouches, and the balloons were emptied each morning. The 24hour output of acid was calculated in m-equiv after determining the concentration of acid by titration with $0 \cdot 1 \mathrm{~N} \mathrm{NaOH}$ to the phenol red end point.

Operations were carried out aseptically under pentobarbital sodium anaesthesia. A Heidenhain pouch was constructed from the greater curvature aspect of the gastric corpus in each dog and the pouch was drained externally by means of a stainless steel cannula. Intravenous fluids were administered for one to two days after operation, and the dogs were then allowed to resume their diet. Gastric secretory outputs were not recorded until the dogs were consuming a normal diet and until the daily secretion of acid had become relatively stable. In most instances this occurred within one week of operation.

During a six-month period an average population of 20 female dogs with Heidenhain pouches was observed carefully for signs of oestrus. Since

Received for publication 1 December 1969.

1Present address: Department of Surgery, University of Florida College of Medicine, Gainesville, Florida 32601, USA. 


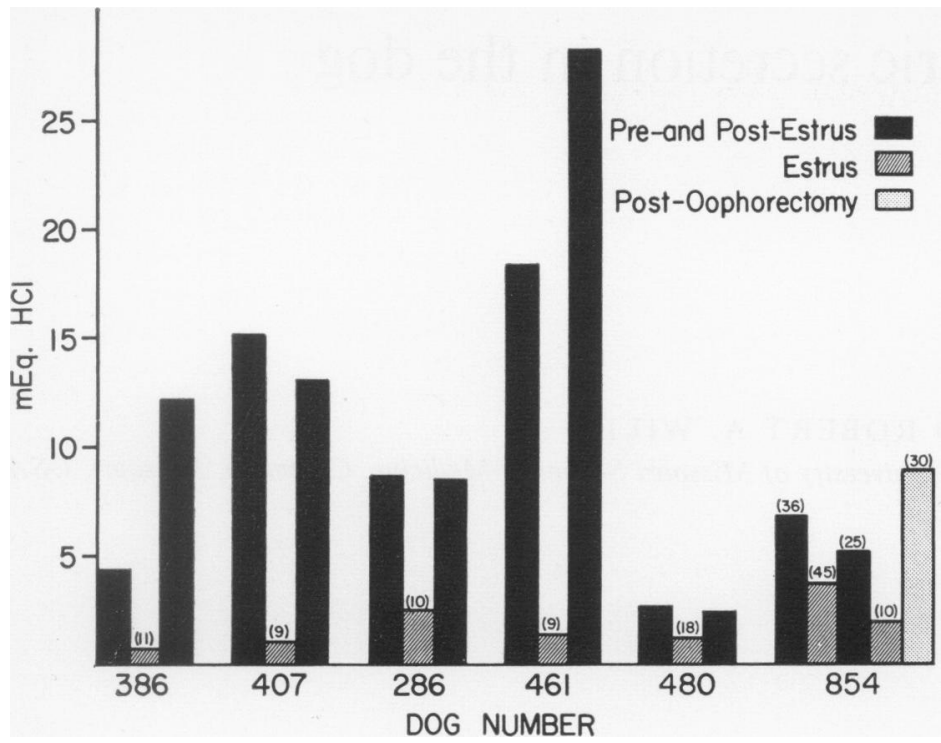

Fig. 1 Mean daily secretion of $\mathrm{HCl}$ preceding, during, and after oestrus. Unless otherwise noted (by the numbers in parentheses) each column represents an average of 14 days.

this normally occurs at intervals of four to 11 months (Eckstein and Zuckerman, 1956) it was anticipated that oestrus would be encountered on at least several occasions during the six-month period. In fact, six bitches exhibited prodromal signs of oestrus, such as swelling of the vulva, sanguineous vaginal discharge, and increased motor activity. Gastric secretory changes coincident with these signs were noted, and the average daily output of acid during this time was calculated and compared with the average acid output during the 14 days immediately preceding and following the secretory changes. One animal (no. 854) which showed signs of oestrus on two occasions less than a month apart was subjected to oophorectomy.

Daily collections of gastric juice were carried out for $\mathbf{3 0}$ or more days in another group of bitches with Heidenhain pouches. After this time five animals underwent bilateral oophorectomy, and the other five underwent celiotomy with exploration of the ovaries but no oophorectomy. Upon recovery, daily collections of gastric juice were resumed and were continued for at least 30 days.

A third group of dogs with Heidenhain pouches, one male and five oophorectomized females, was given oral diethyl stilboestrol in gradually increasing doses. All were started on a dose of $5 \mathrm{mg}$ per day. This was increased in $5 \mathrm{mg}$ increments every two weeks until a dose of $30 \mathrm{mg}$ per day was reached, then in $10 \mathrm{mg}$ increments every two weeks to a maximum of $70 \mathrm{mg}$ per day. Oestrogen administration was stopped before the maximum dose was reached in those instances where a reduction in food intake was observed. Dosage levels extending over a wide range were employed because most previous investigations of the possible influence of oestrogens on gastric secretion have failed to demonstrate a definite oestrogenic effect with small or moderate doses.

\section{Results}

Five of the six bitches who displayed signs of oestrus had marked decreases in Heidenhaino pouch secretion for periods of time varying? between nine and 18 days (Fig. 1). Although the physical signs of approaching oestrus were usually present before the decrease in acid secre-o tion, on occasion the drop in secretion was notede before the onset of oestrus became apparent: In no instance was there a change in food intake during the period of depressed acid secretion. $\vec{\circ}$ Swelling of the vulva usually persisted for a week or more after the gastric secretion had returned to normal. Changes in gastric secretion were sudden rather than gradual, as can be seen in the daily secretion of a typical animal as shown ins Figure 2.

The behaviour of dog no. 854 was somewhat unusual in that signs of oestrus persisted for $\overrightarrow{0}$ one and a half months and were associated with only a modest fall in gastric secretion. Signs of oestrus appeared again 25 days later, and thiso time the drop in secretion was somewhat mores pronounced. After 10 days of persistent signs, of oestrus, oophorectomy was carried out ando was followed by an immediate, sustained, and ${ }^{\circ}$ rather marked rise in gastric acid output (Fig. 1). $\overrightarrow{\overrightarrow{0}}$

The average daily secretion of acid from Heid- 3 enhain pouches before and after oophorectomy in five dogs, or before and after sham oophorectomy in another five dogs, is depicted in Figure $3 \stackrel{0}{\subseteq}$ Changes in secretion were slight and it is clear that neither operation had a definite effect on. acid production from the pouches.

The response to oral diethyl stilboestrol was not constant. Three dogs manifested gastrico hyposecretion but, coincident with this, developed anorexia of such severity that the drug had to bog

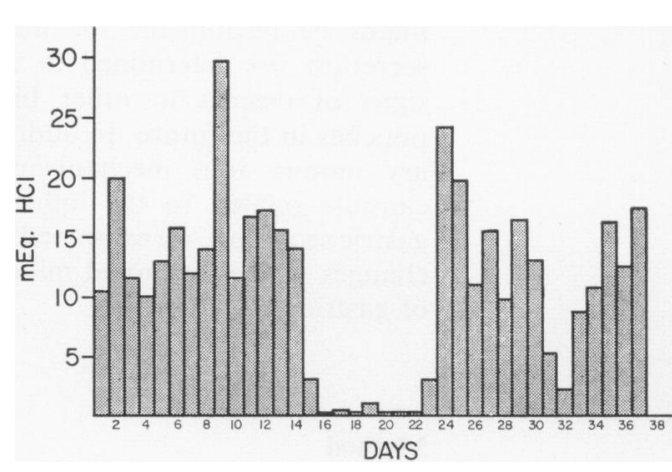

Fig. 2 Dog 407. Daily secretion of $\mathrm{HCl}$ during oestrus and for two weeks before and after oestrus. 


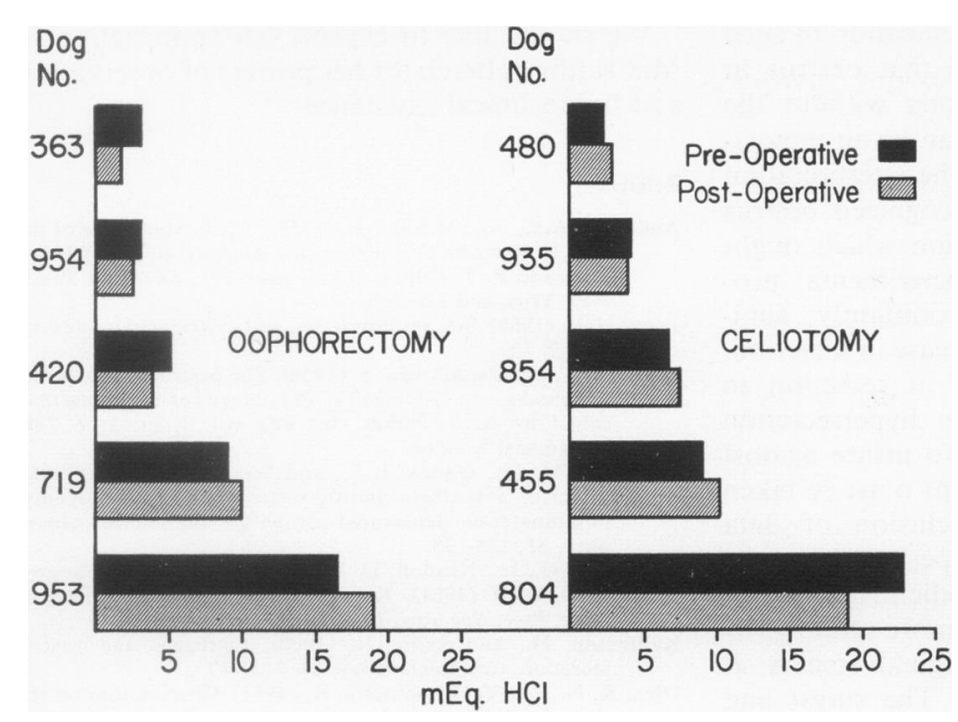

Fig. 3 Mean daily secretion of $\mathrm{HCl}$ before and after oophorectomy (left) or sham oophorectomy (right).

discontinued. The remaining three animals exhibited random changes in secretion (both increases and decreases) with alterations in dosage of stilboestrol; none of these changes were significant. The secretions of all three dogs rose to levels significantly higher $(P=<0.02)$ during the two weeks after oestrogen administration was stopped than the levels during the previous two weeks when the dogs were receiving $70 \mathrm{mg}$ diethyl stilboestrol daily.

\section{Discussion}

Periods of typical oestrus in mongrel bitches were invariably associated with depressed secretion of $\mathrm{HC} 1$ from denervated gastric pouches, a finding which may account for the earlier observation of Winkelstein (1936) that an ulcer of the abdominal wall around the stoma of a subcutaneous gastric pouch healed during oestrus. Since there were no discernible alterations in environment or food intake coincident with secretory change, it is likely that the secretory inhibition was brought about by the hormonal changes which take place during oestrus.

The course of the animal which displayed external signs of oestrus for prolonged periods on two occasions in quick succession is somewhat puzzling. Perhaps this represents an example of the phenomenon of 'polyoestrus' (Andersen and Wooten, 1959). At any rate, it is of interest that oophorectomy in this animal was followed by a sharp and sustained rise in Heidenhain pouch secretion. Whilst this suggests that gastric secretion at the time of oophorectomy was being depressed by heightened production of ovarian hormones, additional observations would be required for confirmation of this hypothesis.

Our studies of oophorectomy in the Heidenhain pouch animal were undertaken in order to ascertain if the canine ovary exerts an influence on gastric secretion at times other than during oestrus. It is apparent from the secretory data in the oophorectomized dogs that no such effect was demonstrated. These results are in agreement with those of Singh and Shukla (1959), who found that oophorectomy did not result in increased gastric acidity in the pylorus ligated rat, and with those of Baron (1966), who found that oophorectomy did not alter the output of gastric acid in dogs given histamine intravenously. Eisenberg, Owens, and Woodward (1965), on the other hand, noted a slight increase in gastric secretion after oophorectomy in dogs who were being given testosterone, and felt that in this circumstance the ovaries were probably exerting a restraining influence on the androgenic stimulation of gastric secretion.

There have been numerous previous studies of the effect of oestrogen on gastric secretion. Various preparations and dosages of oestrogen have been found to have no effect on histamine-stimulated secretion in the dog (Griffen, Nicoloff, Stone, and Wangensteen, 1961; Baron, 1966) or on basal and histamine-stimulated secretion in man (Schiff, Felson, Graff, and Meyer, 1938; Parbhoo and Johnston, 1966; Kaufmann and Spiro, 1968) and the monkey (Kaufmann and Spiro, 1968). Ojha and Wood (1950), however, found that stilboestrol lowered the gastric secretory response to histamine in the anaesthetized cat and Ojha and Vankatachalam (1951) reported that stilboestrol reduced the acidity elicited by a fractional test meal in duodenal ulcer patients. Our results neither document nor disprove the existence of an oestrogenic effect on gastric secretion. Although definite and sustained reduction in acid output was not seen without a concomitant decrease in food intake, the increases in secretion seen after discontinuance of the drug suggest the possibility of some inhibitory oestrogenic effect. Perhaps the serum concentration of oestrogen, or its concentration in relation to another hormone, must be within a certain critical range in order for a gastric inhibitory effect to become manifest.

The observation that canine oestrus is associated with gastric secretory inhibition carries with it important implications, both theoretical and practical, for the gastric physiologist. In addition to re-emphasizing the fact that female hormones are capable of influencing gastric function, and 
providing further impetus for delineation of such humoral effects, it also implies that oestrus in experimental animals, if it occurs without the knowledge of the investigator, can be an important potential source of error in the interpretation of gastric secretory data. Unrecognized oestrus could cause decreases in secretion which might be attributed erroneously to experimental procedures being carried out concomitantly; similarly, oestrus might mask an increase in secretion, or actually cause a reduction in secretion in experimental situations where hypersecretion would otherwise be observed. To insure against this potential source of error steps must be taken to prevent the inadvertent inclusion of data collected from bitches during the period of oestrus. This could be achieved by periodic inspection of animals for signs of oestrus or, more reliably, by the routine performance of vaginal smears at regular intervals in all bitches. The surest and most effective way to prevent errors from this source, and to avoid the necessity of having to discard data from a bitch who is discovered to be in heat, would be to remove the ovaries from all female animals before they were used in studies in gastric secretion.

This work was supported by grant AM-07750 from the United States Public Health Service.
We should like to express our appreciation to Mrs Kathryn Berck for her powers of observation and her technical assistance.

\section{References}

Andersen, A. C., and Wooten, E. (1959). The estrous cycle of the dog. In Reproduction in Domestic Animals, edited by $\mathrm{H}$. H. Cole and P. T. Cupps, vol. 1, page 391. Academic Press, New York and London.

Baron, J. H. (1966). Sex, sex hormones, and gastric acid in the dog. Gut, 7, 709.

Eckstein, P., and Zuckerman, S. (1956). The oestrous cycle in the mammalia. In Marshall's Physiology of Reproduction, $\vec{O}$ edited by A. S. Parkes, 3rd ed., vol. 1, Pt. 1, p. 288. Longmans, London.

Eisenberg, M. M., Owens, J. E., and Woodward, E. R. (1965). Effect of a synthetic androgen (testoste:one $\beta$ cyclopentyl $\vec{Q}$ propionate) on denervated canine gastric pouches. Amer. Surg, 31, 135-138.

Griffin, W. O., Jr., Nicoloff, D. M., Stone, N. H., and Wangen- $\overrightarrow{-}$ steen, O. H. (1961). Role of the sex hormones in peptic $\overrightarrow{\vec{A}}$ ulcer. Proc. Soc. exp. Biol. (N.Y.), 106, 101-104.

Kaufmann, H., and Spiro, H. (1968). Estrogens and gastric $\infty$ secretion. Gastroenterology, 54, 913-917.

Ojha, K. N., and Venkatachalam, K. (1951). Observations on the use of stilbesterol in the treatment of peptic ulcer. Gastroenterology, 18, 100-103.

Ojha, K. N., and Wood, D. R. (1950). The inhibitory effect of stilboesterol on gastric secretion in cats. Brit.J. Pharmacol., 5, 389-394.

Parbhoo, S. P., and Johnston, I. D. A. (1966). Effects of oestrogens and progesterogens on gastric secretion in patients with $\mathbb{\triangle}$ duodenal ulcer. Gut, 7, 612-618.

Schiff, L., Felson, H., Graff, J., and Meyer, B. (1938). The effect of $\vec{\varphi}$ esterogenic hormone on gastric acidity. Amer.J. dig. Dis., 5, $\supset$ 292-294.

Singh, G. B., and Shukla, R. C. (1959). Effect of gonadectomy on experimental peptic ulceration. Ind. J. med. Res., 47, 287-293.

Winkelstein, A. (1936). Observations on ulcerations adjacent to $\bar{\partial}$ experimental gas:ric pouches in dogs. Amer. J. dig. Dis., 3, ֶै 229-231. 